\title{
The Effect of Sodium Hyaluronate plus Sodium Chondroitin Sulfate Solution on Peritendinous Adhesion and Tendon Healing: An Experimental Study
}

\author{
Hacı Bayram Tosun ${ }^{1}$, Seyit Ali Gümüştaş ${ }^{1}$, Mustafa Kom², Abuzer Uludağ ${ }^{1}$, Sancar Serbest ${ }^{3}$, Yesari Eröksüz ${ }^{4}$ \\ ${ }^{1}$ Department of Orthopaedics and Traumatology, Adıyaman University School of Medicine, Adiyaman, Turkey \\ ${ }^{2}$ Department of Surgery, Frrat University School of Veterinary Medicine, Elazı̆ \\ ${ }^{3}$ Department of Orthopaedic Surgery, İnegöl State Hospital, Bursa, Turkey \\ ${ }^{4}$ Department of Pathology, Firat University School of Veterinary Medicine, Elazı̆g, Turkey
}

Background: Adhesion formation following tendon injury is a serious clinical problem.

Aims: In this experimental study, the effects of the combination of sodium hyaluronate (HA) and chondroitin sulfate (CS) on peritendinous adhesion and tendon healing were evaluated.

Study Design: Animal experimentation.

Methods: Twenty-one mature Sprague Dawley male rats were randomly divided into three equal groups. The rats' Achilles tendons were cut and repaired with a modified Kessler technique. About 0.25 and $0.50 \mathrm{~mL}$ of the HA and CS (HA+CS) combination were injected subcutaneously into the repair site of the rats in groups 1 and 2, respectively, on days $0,3,7$, and 10 . The subjects in group 3 were used as the control group. At 6 weeks, all rats were euthanized. The tenotomy site was examined macroscopically in all animal subjects. Four samples were assigned to the histopathological examination group, and the others were assigned to the biomechanical assessment group.
Results: Inflammation and adhesion in both treatment groups were observed at a lower rate than in the control group. The collagen filaments in both treatment groups were regular and the number was low when compared to the control group. However, there was no statistically significant difference between group 1 and the control group. The quantity, quality, and grade of the adhesions were statistically significantly lower in group 2 when compared with the other groups. The mean maximum stress strength in group 2 was statistically significantly higher than that in group 1 and the control group.

Conclusion: Local administration of the $\mathrm{HA}+\mathrm{CS}$ combination solution is a valid tool for preventing peritendinous adhesion after extrasynovial tendon repair such as Achilles tendon, and is a treatment option in such cases.

Keywords: Chondroitin sulfate, hyaluronate, peritendinous adhesion, tendon healing
The restoration of gliding function following tendon injury is a major problem for hand surgeons (1). Various synthetic materials, such as FocalSeal-L (2), Seprafilm ${ }^{\circledR}$ (3), glycosaminoglycan hydrogel films (4), polyethylene film (5), and carbodiimide derivatized gelatin/hyaluronic acid (6) have been used to prevent this problem. However, some materials failed because they stimulated a severe inflammatory response or allowed ingrowth of adhesion around the edges of the material. Other materials prevented nutrient diffusion to the healing tendon leading to tendon necrosis (2). Targeting local cells that contribute to restrictive adhesion may play an important role in preventing peritendinous adhesion and improving functional results. Hyaluronic acid and many other substances, such as aprotinin (7), 5-fluorouracil (8), mannose6-phosphate (9), and beta-aminopropionitrile (10) have been used to resolve this problem (11).

Glycosaminoglycans (GAGs) such as sodium hyaluronate (HA) and glucosamine N-chondroitin sulfate (glcN-CS) are

This study was presented as an oral presentation at the $14^{\text {th }}$ National Hand and Upper Extremity Surgery Congress, 15-18 May 2014, Bursa, Turkey.

Address for Correspondence: Dr. Hacı Bayram Tosun, Department of Orthopaedics and Traumatology, Adıyaman University School of Medicine, Adıyaman, Turkey Phone: +905334497699 e-mail: bayramtosun@hotmail.com

Received: 10 March $2014 \quad$ Accepted: 16 September 2015 •DOI: 10.5152/balkanmedj.2016.140172

Available at www.balkanmedicaljournal.org

Tosun HB, Gümüştaş SA, Kom M, Uludağ A, Serbest S, Eröksüz Y. The effect of sodium hyaluronate+sodium chondroitin sulfate solution on peritendinous adhesion and tendon healing: An experimental study. Balkan Med J 2016;33:258-66 
polysaccharides with aminoglucose content and are found in the extracellular matrix of all vertebrates as well as in some bacteria (12). GAGs provide a well-hydrated pericellular environment. In this way, they may contribute to the wound healing process by creating an appropriate environment for growth, leading to the accumulation of other matrix proteins, the formation of growth and differentiation factors, and cell migration (4). Furthermore, GAGs influence specific interactions that affect important processes such as the formation of collagen fibrils, cell-cell interactions, growth factors binding, and cell regulation by influencing physical processes such as ion transport, nutrient diffusion, and water retention (13).

Sodium hyaluronate is a widely used agent, and local administration of HA aims at preventing adhesion following tendon repair $(14,15)$. Oral applications of glcN-CS have also been reported to be beneficial in tendon healing and in preventing adhesion $(16,17)$. Intravesical instillation of the sodium hyaluronate and chondroitin sulfate (CS) combination has been used for treating chronic cystitis (18). However, few studies have been conducted on the use of $\mathrm{HA}$ and $\mathrm{CS}$ combination $(\mathrm{HA}+\mathrm{CS})$ as a local injection in orthopedic practice. In a review of the literature, three studies were found on the use of HA and CS for treating osteoarthritis $(19,20)$ and on the effects of HA and CS on the formation of adhesion following tendon repair (21).

Given this background, we hypothesized that a combined composite solution of sodium hyaluronate and chondroitin sulphate might be effective in preventing peritendinous adhesion after extrasynovial tendon repair such as Achilles tendon.

In this study, we aimed at analyzing the effects of the local application of the $\mathrm{HA}+\mathrm{CS}$ combination solution injection on peritendinous adhesion and the tendon healing process.

\section{MATERIALS AND METHODS}

The study was begun after ethics committee approval was obtained from the Institutional Ethical Board of Animal Assays of Firat University (Reference Number: 2012/2013-118). Our study was conducted according to the Guidelines of the Care and the Use of the Laboratory Animals. Twenty-one mature, male Sprague Dawley rats 300-320 g in weight were randomly divided into three equal groups. Each subject underwent an Achilles tenotomy and primary repair procedure. In groups 1 and 2, $0.25 \mathrm{~mL}$ and $0.50 \mathrm{~mL}$, respectively, of a solution containing a $\mathrm{HA}+\mathrm{CS}$ combination $(800 \mathrm{mg}$ sodium hyaluronate combined with $1 \mathrm{~g}$ chondroitin sulphate $/ 50 \mathrm{~mL}$ ) (Ialuril; IBSA Farmaceutici Italia S.r.l., Lodi, Italia) was injected subcutaneously to the repair site on days $0,3,7$, and 10. Group 3 was the control group. The surgical wound was closed with dressings, and joint movements were not restricted following the procedure. All rats were euthanized at 6 weeks.

\section{Surgical procedure}

General anesthesia was induced with an intramuscular injection of $50 \mathrm{mg} / \mathrm{kg}$ ketamine HCL and was maintained with an intramuscular injection of $5 \mathrm{mg} / \mathrm{kg}$ xylazine HCL and $0.3 \mathrm{mg} /$ $\mathrm{kg}$ ketamine HCL. The left hind limb of the rats was shaved, scrubbed with $10 \%$ povidone iodine, and draped in a sterile fashion. Then a longitudinal incision $1.5-2 \mathrm{~cm}$ long was made laterally to the Achilles tendon. The subcutaneous tissue was dissected, and the full thickness of the Achilles tendon was tenotomized using a number 15 bistoury. All cut tendons were repaired with a modified Kessler suture technique using 3-0 polypropylene suture (Foosin Medical Supplies Inc. Ltd; Shandong, China). The skin incision in the surgical repair site was closed with en block sutures including paratenon using 2-0 polypropylene (Foosin Medical Supplies Inc., Ltd; Shandong, China) suture material. A HA+CS combination solution was subcutaneously injected to the repair area of the subjects in the treatment groups after the wound was closed. No substance was used in the control group since the saline solution might increase the formation of adhesion (22). The wound was sutured and then closed with a dressing, and free joint movements were permitted. Daily nutrition was provided with adequate pellets and water. In groups 1 and 2, the HA+CS solution was administered subcutaneously to the peritendinous area on days 0,3 , 7 , and 10. All subject animals were euthanized at 6 weeks using the carbon dioxide inhalation method. The tenotomy site was examined in all subjects (Figure 1). Then the Achilles tendon was removed together with the calcaneus bones. Tendon thickness was measured at the tenotomy site, and adhesion formation was observed macroscopically by a blinded researcher. Four samples in the groups randomly and in a blinded fashion assigned to the histopathological examination group, and the others were assigned to the biomechanical assessment group. Randomization was performed by a blinded researcher who did not know the groups. Tissues assigned to the histopathological evaluation group were fixed using 10\% formalin and embedded in paraffin blocks. Samples were sectioned into slices $5 \mu \mathrm{m}$ thick and were stained with hematoxylin-eosin (H-E) and Masson's trichrome. Preparations were examined under an Olympus BX51 light microscope (Olympus; Tokyo, Japan) in a single blinded design. A grading system defined by Tang et al. (23) was used for macroscopic and microscopic adhesion scoring (Table 1, 2).

Achilles tendon samples obtained with a sound calcaneus attached to one end of the tendon were stored at room temperature for $1 \mathrm{~h}$. Biomechanical tests of each tendon were performed using the Shimadzu Autograph AG-X/50kN testing machine (Shimadzu Corp; Kyoto, Japan) in the Material Laboratory of the Material and Metallurgy Engineering Department of Technology Faculty in our university. The specimens 

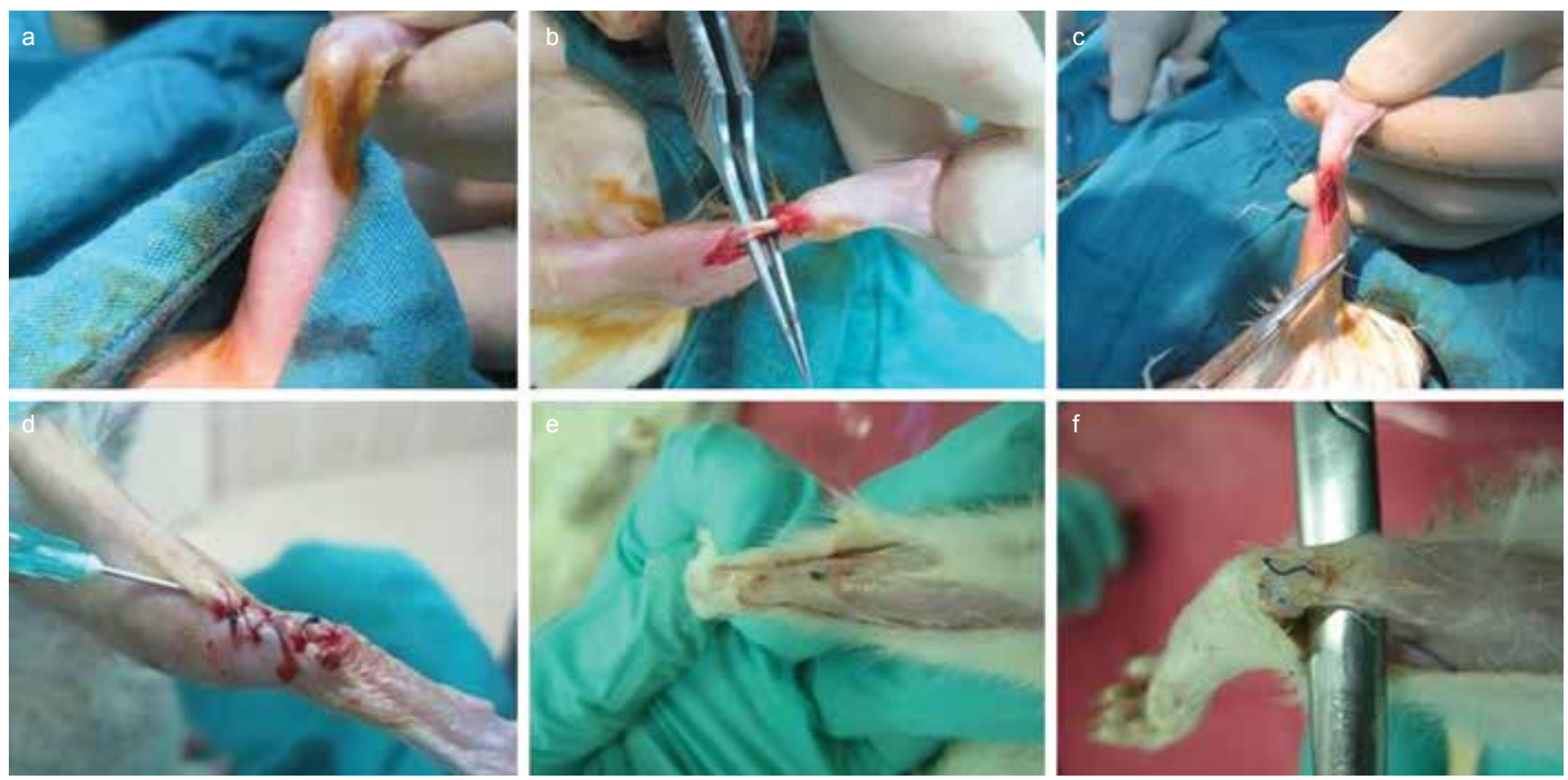

FIG. 1. Surgical method: Shaved and disinfected (a), dissected achilles tendon (b), sutured tendon using modified Kessler technique (c), closure and peritendinous $\mathrm{HA}+\mathrm{CS}$ injection (d), healing observed in all tendon (f), dissection of healed tendon (e)

TABLE 1. Macroscopic grading system for adhesions according to Tang et al. (23)

\begin{tabular}{lc}
\hline Points & Features of adhesions \\
\hline Length (quantity) & No adhesions \\
0 & $<5 \mathrm{~mm}$ \\
1 & 5 to $10 \mathrm{~mm}$ \\
2 & $>10 \mathrm{~mm}$ \\
3 & \\
Density and tolerance for mobility (quality) & No adhesions \\
0 & Loose, elastic, mobile \\
1 & Moderate mobility \\
2 & Rigid, dense, immobile \\
3 & \\
Grading of adhesions & Absent \\
0 & Inferior \\
1 to 2 & Medium \\
3 to 4 & Severe \\
5 to 6 & \\
\hline
\end{tabular}

were mounted between two metal clamps and were subjected to tensile deformation at a strain rate of $0.22 \mathrm{~mm} / \mathrm{sec}$ with $1 \mathrm{~N}$ pre-load (Figure 2). The measurements were recorded using a Trapezium 2.0 v.2.23 (Shimadzu Corp; Kyoto, Japan) test protocol. The ultimate tensile strength and the ultimate strain were determined. Biomechanical tests were also performed as a single blinded design.
TABLE 2. Histopathological evaluation of adhesions according to Tang et al. (23)

\begin{tabular}{lc}
\hline Points & Features of adhesions \\
\hline Quantity & No apparent adhesions \\
0 & A number of scattered filaments \\
1 & A large number of filaments \\
2 & Countless filaments \\
3 & \\
Quality & No apparent adhesions \\
0 & Regular, elongated, fine, filamentous \\
1 & Irregular, mixed, shortened, filamentous \\
2 & Dense, not filamentous \\
3 & \\
Grading of adhesions & None \\
0 & Slight \\
2 & Moderate \\
3 to 4 & Severe \\
5 to 6 & \\
\hline
\end{tabular}

\section{Statistical analysis}

The sample size for groups was adequate to detect significant biomechanical and histopathological improvement, in agreement with the study by Ozer et al. (16) and Ozboluk et al. (24). Furthermore, variance analysis revealed the homogeneity of the groups. Thus, the sample size was adequate for histological analysis according to Kuzma et al. (25). The sample 


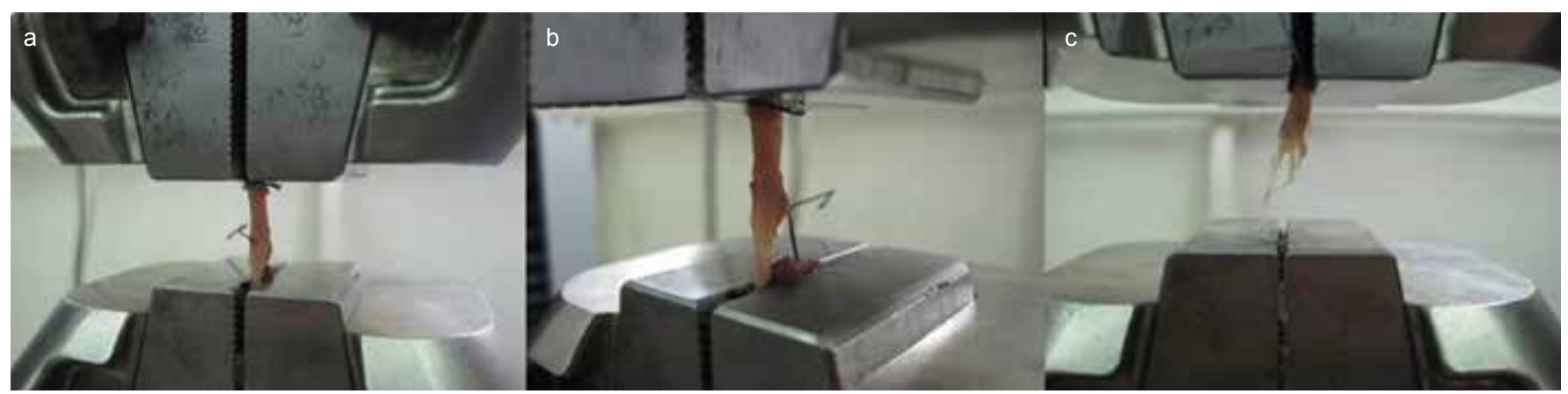

FIG. 2. Biomechanical strength: a) early stage (b), mid-stage (b), stage of maximum stress (c)

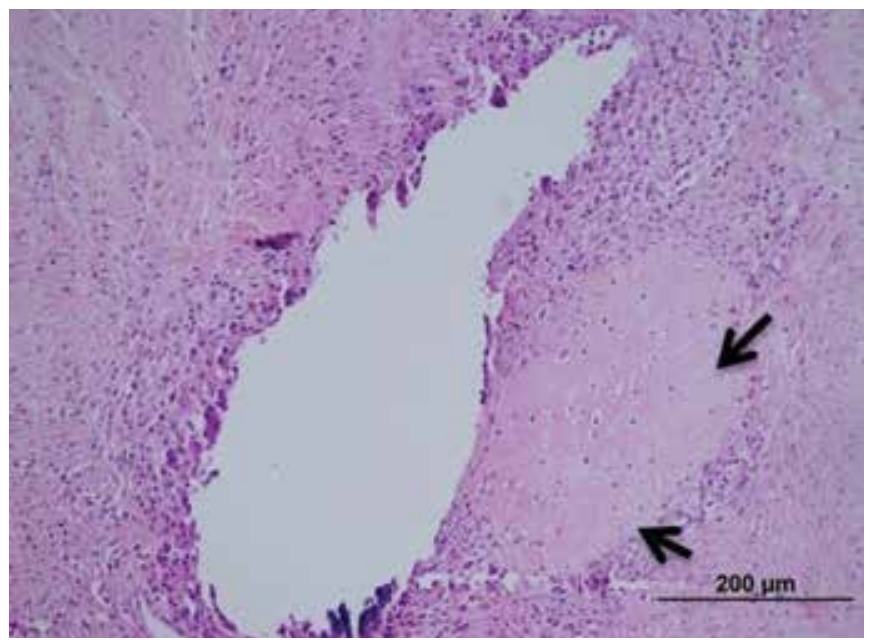

FIG. 3. Cartilaginous metaplasia formation around the suture material (arrows) first group. (H-E)

TABLE 3. Tendon thickness after healing

\begin{tabular}{|c|c|c|c|c|c|c|c|}
\hline & \multicolumn{2}{|c|}{ Group $1(\mathrm{n}=7)$} & \multicolumn{2}{|c|}{ Group $2(\mathrm{n}=7)$} & \multicolumn{2}{|c|}{$\begin{array}{c}\text { Group } 3 \\
\text { (Control) }(\mathrm{n}=7)\end{array}$} & \multirow[b]{2}{*}{$\mathrm{p}$} \\
\hline & $\mathrm{mm}$ & mean $\pm \mathrm{SD}$ & $\mathrm{mm}$ & mean \pm SD & $\mathrm{mm}$ & mean $\pm \mathrm{SD}$ & \\
\hline \multirow{7}{*}{$\begin{array}{l}\text { Tendon } \\
\text { thickness }\end{array}$} & 3 & \multirow{7}{*}{$3.29 \pm 0.49$} & 3 & \multirow{7}{*}{$3.14 \pm 0.69$} & 3 & \multirow{7}{*}{$3 . \pm 0.58$} & \multirow{7}{*}{0.67} \\
\hline & 3 & & 4 & & 4 & & \\
\hline & 3 & & 4 & & 3 & & \\
\hline & 4 & & 3 & & 2 & & \\
\hline & 3 & & 2 & & 3 & & \\
\hline & 3 & & 3 & & 3 & & \\
\hline & 4 & & 3 & & 3 & & \\
\hline
\end{tabular}

size for the biomechanical test was determined with Minitab 14.0 software, in agreement with the mean force needed for rerupture in Ozboluk et al.'s (24) study. The power of the study for the biomechanical test was 0.83 . Following the homogeneity of variance analysis, a one-way ANOVA test was applied for biomechanical analysis. To detect statistically significant differences, the Tukey honest significant difference (HSD) test was used as a post-hoc analysis to detect the groups that created the difference. Count data were compared with using the Kruskal-Wallis and then the Mann-Whitney U-test. To determine the average of the differences on the non-parametric data, it was applied the manual adjustment for $\mathrm{p}$ value by Bonferroni correction method after Mann-Whitney U-test. All statistical analyses were performed with using an IBM SPSS Statistics 21.0 (IBM Corp; Armonk, NY, USA) program. $P$ value $<0.05$ was considered statistically significant.

\section{RESULTS}

\section{Macroscopic findings}

There were no tendon ruptures and wound infection in any animal group. No significant difference in mean tendon thickness at the healing site was detected among the groups (Table 3).

Macroscopic findings concerning adhesions are shown in Table 4 . The quantity, quality of the adhesions were significantly lower in group 2 when compared with the other groups. The grade of the adhesions was significantly lower in both treatment groups when compared to the control group; however, there was no statistically significant difference between both treatment groups.

\section{Histopathological findings}

The inflammation and adhesions in group 1 were milder than those in the control group; however, formation of cartilaginous metaplasia on the tendons, particularly around the suture materials, was observed. In group 1, a mild increase was observed in the number of collagen filaments, and the fibrils were partly irregular and shortened compared to the control group (Figure 3), but did not differ statistically significantly between group 1 and the control group. Inflammation and apparent adhesion in group 2 were observed at a lower rate when compared to group 1 and the control group. The formation of fibrocartilaginous metaplasia was also recorded 
in group 2. The collagen filaments in both treatment groups were regular and fewer when compared to the control group (Figure 4). However, there was no statistically significant difference between group 1 and the control group. In contrast to both treatment groups, the muscular tissues and fascicles surrounding the tendons in group 3 (the control group) were unorganized with each other and adhered to the granulation tissue that was rich in cells. In addition, intensive inflammatory infiltration consisting of lymphocytes and macrophages at the adhesion site was observed in the control group (Figure 5). The dense and irregular filaments increased, and there was no cartilaginous metaplasia in the control group.

The quality, quantity, and grade of adhesions of the histopathological assessment are shown in Table 5. The quality, quantity, and grade were statistically significantly lower in group 2 when compared to the other groups. The quality, quantity, and grade were lower in group 1 when compared to the control group but did not differ statistically significantly between group 1 and the control group.

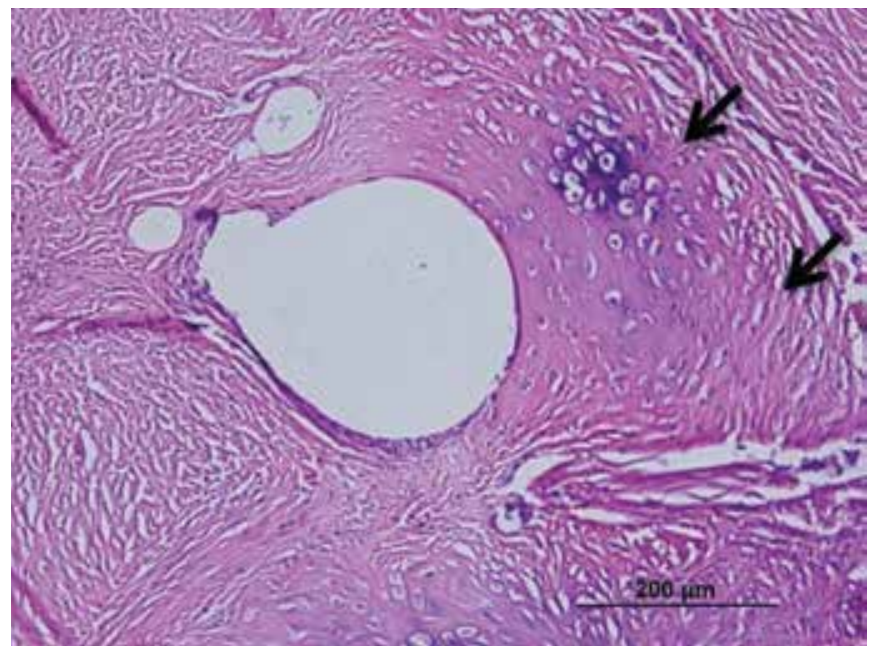

FIG. 4. Cartilaginous metaplasia formation around the suture material (arrows) second group (H-E)

\section{Biomechanical findings}

The maximum stress strength that tenotomized Achilles tendons is shown in Table 6. The mean maximum stress strength in group 2 was statistically significantly higher than that in group 1 and the control group but did not differ significantly between group 1 and the control group (group 3).

\section{DISCUSSION}

Adhesion formation continues to be a major clinical problem following tendon injury $(26,27)$. For the best sliding function of the tendon, various physical, surgical, and pharmacological options were investigated to prevent peritendinous adhesion without disturbing the healing process. However, the scientific evidence underlying these methods should be meticulously analyzed before they are widely introduced into routine clinical practice (28).

Recently, interest in hyaluronic acid has increased in intrinsic adhesion restriction and anti-inflammatory effects (29).

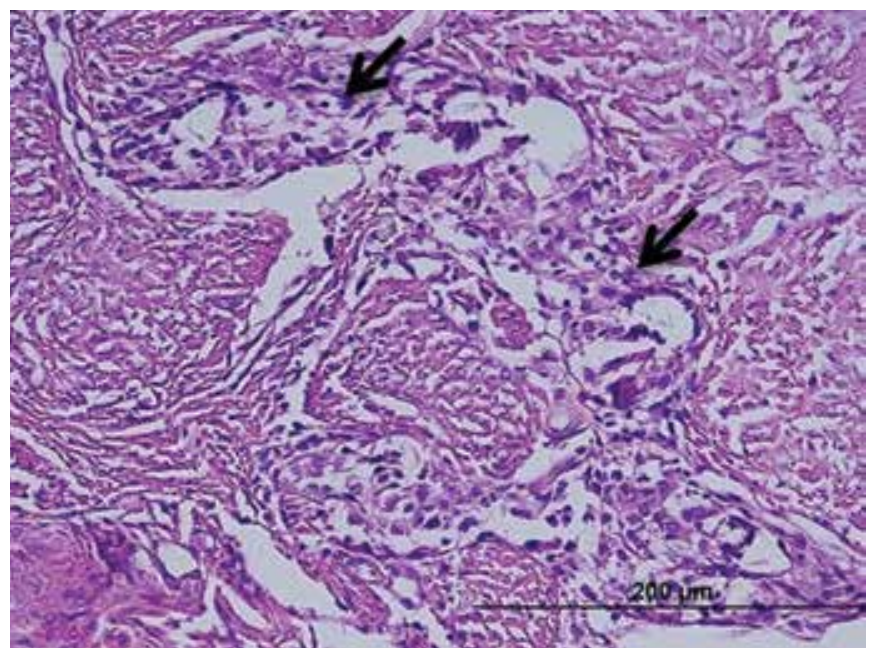

FIG. 5. Partially organized granulation tissue rich in cells, among the tendons (arrows), control group (H-E)

TABLE 4. Macroscopic grading system for adhesions according to Tang et al. (23)

\begin{tabular}{|c|c|c|c|c|c|c|c|c|}
\hline \multicolumn{9}{|c|}{ Features of adhesions (Points) } \\
\hline \multicolumn{3}{|c|}{ Length (quantity) mean $\pm \mathrm{SD}$} & \multicolumn{3}{|c|}{ Density and tolerance for mobility (quality) mean \pm SD } & \multicolumn{3}{|c|}{ Grading of adhesions mean \pm SD } \\
\hline Group $1(\mathrm{n}=4)$ & Group $2(n=4)$ & Group $3(n=4)$ & Group1 $(\mathrm{n}=4)$ & Group $2(n=4)$ & Group $3(n=4)$ & Group $1(n=4)$ & Group $2(n=4)$ & Group $3(n=4)$ \\
\hline $1.0 \pm 0.8$ & $0.4 \pm 0.5$ & $2.3 \pm 0.8$ & $1.1 \pm 0.7$ & $0.7 \pm 0.8$ & $2.1 \pm 0.4$ & $2.7 \pm 0.8$ & $1.4 \pm 1.0$ & $5.4 \pm 0.5$ \\
\hline \multicolumn{9}{|c|}{$\mathrm{p}$} \\
\hline \multicolumn{3}{|c|}{ The compared groups of quantity } & \multicolumn{3}{|c|}{ The compared groups of quanlity } & \multicolumn{3}{|c|}{ The compared groups of grade } \\
\hline Group 1 vs 2 & Group 1 vs 3 & Group 2 vs 3 & Group 1 vs 2 & Group 1 vs 3 & Group 2 vs 3 & Group 1 vs 2 & Group 1 vs 3 & Group 2 vs 3 \\
\hline $\mathrm{p}>0.05$ & $\mathrm{p}>0.05$ & $\mathrm{p}<0.05$ & $\mathrm{p}>0.05$ & $\mathrm{p}>0.05$ & $\mathrm{p}<0.05$ & $\mathrm{p}>0.05$ & $\mathrm{p}<0.05$ & $\mathrm{p}<0.05$ \\
\hline
\end{tabular}

(Group 3=Control group) 
TABLE 4. Macroscopic grading system for adhesions according to Tang et al. (23)

\begin{tabular}{|c|c|c|c|c|c|c|c|c|}
\hline \multicolumn{9}{|c|}{ Features of adhesions (Points) } \\
\hline \multicolumn{3}{|c|}{ Length (quantity) mean $\pm \mathrm{SD}$} & \multicolumn{3}{|c|}{ Density and tolerance for mobility (quality) mean $\pm \mathrm{SD}$} & \multicolumn{3}{|c|}{ Grading of adhesions mean $\pm \mathrm{SD}$} \\
\hline Group $1(n=4)$ & Group $2(n=4)$ & Group $3(n=4)$ & Group1 $(n=4)$ & Group $2(n=4)$ & Group $3(n=4)$ & Group $1(n=4)$ & Group $2(n=4)$ & Group $3(n=4)$ \\
\hline $1.0 \pm 0.8$ & $0.4 \pm 0.5$ & $2.3 \pm 0.8$ & $1.1 \pm 0.7$ & $0.7 \pm 0.8$ & $2.1 \pm 0.4$ & $2.7 \pm 0.8$ & $1.4 \pm 1.0$ & $5.4 \pm 0.5$ \\
\hline \multicolumn{9}{|c|}{$\mathrm{p}$} \\
\hline \multicolumn{3}{|c|}{ The compared groups of quantity } & \multicolumn{3}{|c|}{ The compared groups of quanlity } & \multicolumn{3}{|c|}{ The compared groups of grade } \\
\hline Group 1 vs 2 & Group 1 vs 3 & Group 2 vs 3 & Group 1 vs 2 & Group 1 vs 3 & Group 2 vs 3 & Group 1 vs 2 & Group 1 vs 3 & Group 2 vs 3 \\
\hline $\mathrm{p}>0.05$ & $\mathrm{p}>0.05$ & $\mathrm{p}<0.05$ & $\mathrm{p}>0.05$ & $\mathrm{p}>0.05$ & $\mathrm{p}<0.05$ & $\mathrm{p}>0.05$ & $\mathrm{p}<0.05$ & $\mathrm{p}<0.05$ \\
\hline
\end{tabular}

Group 3: control group

TABLE 5. Histopathological evaluation of adhesions according to Tang et al. (23)

\begin{tabular}{|c|c|c|c|c|c|c|c|c|}
\hline \multicolumn{9}{|c|}{ Features of adhesions (Points) } \\
\hline \multicolumn{3}{|c|}{ Quantity (mean \pm SD) } & \multicolumn{3}{|c|}{ Quality (mean $\pm \mathrm{SD}$ ) } & \multicolumn{3}{|c|}{ Grading of adhesions (mean $\pm \mathrm{SD}$ ) } \\
\hline Group $1(\mathrm{n}=4)$ & Group $2(n=4)$ & Group $3(n=4)$ & Group1 (n=4) & Group $2(n=4)$ & Group $3(n=4)$ & Group $1(n=4)$ & Group $2(n=4)$ & Group $3(n=4)$ \\
\hline $0.8 \pm 0.5$ & $0.3 \pm 0.5$ & $2.8 \pm 0.5$ & $1.0 \pm 0.8$ & $0.3 \pm 0.5$ & $2.8 \pm 0.5$ & $1.8 \pm 1.3$ & $0.8 \pm 1.0$ & $5.3 \pm 0.5$ \\
\hline \multicolumn{9}{|c|}{$\mathrm{p}$} \\
\hline \multicolumn{3}{|c|}{ The compared groups of quantity } & \multicolumn{3}{|c|}{ The compared groups of quality } & \multicolumn{3}{|c|}{ The compared groups of grade } \\
\hline Group 1 vs 2 & Group 1 vs 3 & Group 2 vs 3 & Group 1 vs 2 & Group 1 vs 3 & Group 2 vs 3 & Group 1 vs 2 & Group 1 vs 3 & Group 2 vs 3 \\
\hline $\mathrm{p}>0.05$ & $\mathrm{p}>0.05$ & $\mathrm{p}<0.05$ & $\mathrm{p}>0.05$ & $\mathrm{p}>0.05$ & $\mathrm{p}<0.05$ & $\mathrm{p}>0.05$ & $\mathrm{p}>0.05$ & $\mathrm{p}<0.05$ \\
\hline
\end{tabular}

TABLE 6. Ultimate endurance of all subjects in the groups

\begin{tabular}{|c|c|c|}
\hline Groups & $\begin{array}{l}\text { maximum stress } \\
(\text { mean } \pm \text { SD })\end{array}$ & $\mathrm{p}$ \\
\hline \multirow[t]{2}{*}{ Group $1(\mathrm{n}=3)$} & $7,4 \pm 0,5$ & Group 1 vs $2, p=0.006^{*}$ \\
\hline & & Group 1 vs $3, p=0.324$ \\
\hline \multirow[t]{2}{*}{ Group $2(n=3)$} & $9,3 \pm 0,7$ & Group 2 vs $1, p=0.006^{*}$ \\
\hline & & Group 2 vs $3, \mathrm{p}=0.001^{* *}$ \\
\hline \multirow[t]{2}{*}{ Group 3 (Control) $(\mathrm{n}=3)$} & $6,8 \pm 0,1$ & Group 3 vs $1, p=0.324$ \\
\hline & & Group 3 vs $2, p=0.001 * *$ \\
\hline
\end{tabular}

Hyaluronic acid stimulates mitosis and migration in epithelial cells and fibroblasts during the proliferative stage of wound healing (30). Glycosaminoglycans such as HA and glcN-CS contribute to the transformation of young tenoblasts into mature tenoblasts and tenocytes (17). As demonstrated in previous studies, use of HA after tendon repair promotes tendon healing and reduces adhesion formation $(14,15)$. In a study on the effects of Hylan G-F 20 in rats in which Achilles tendon degeneration was produced, Tatari et al. (31) reported a statistically significant difference in the histopathological changes in the early term. Ozgenel (11) emphasized that despite the lack of difference in tendon healing, use of the amniotic membrane and hyaluronic acid combination following flexor ten- don surgery was effective in preventing adhesion in a chicken model. Menderes et al. (3) reported that peritendinous adhesions following flexor tendon repairs could be decreased with Seprafilm ${ }^{\circledR}$, and collagen fibers had more organized arrangements compared with the control group. In experimental animal studies on the effects of oral glcN-CS on the rat Achilles tendon, Özer et al. (16) reported less inflammation, more regularly arranged collagen formation, and significantly higher levels of tendon tensile strength associated with oral glcN-CS use. In our study, we observed that the collagen filaments in both treatment groups were regular and the number was low compared to the control group. Furthermore, there were less inflammatory infiltration and adhesion formation at the repair area in both treatment groups when compared to the control group; however, there was no statistically significant difference between group 1 and the control group.

Few studies have been conducted on the use of $\mathrm{HA}+\mathrm{CS}$ as local injections in orthopedic practices (21). Combination treatment of HA and CS in tendon repair has been demonstrated to decrease lymphocyte and macrophage infiltration, increase vasculogenesis, increase the number and maturity of tenocytes, and reduce adhesion formation. In addition, the combination treatment improves the differentiation, maturation, density, and alignment of the collagen and elastic fibrils. Ultimately, the treatment contributes positively to the 
restoration of the tendon (17). In previous studies, glcN-CS given orally and local administration of HA following tendon repair have been demonstrated to reduce adhesion formation and positively contribute to biomechanical and morphological restoration of the tendon $(16,17)$. Oryan et al. (17) reported that the combined treatment of HA and glcN-CS efficiently restored the biomechanic and morphologic characteristics of flexor tendon injuries in rabbits. The researchers injected HA subcutaneously in the lesion on days 3, 7, and 10 and administered glcN-CS orally. The capitation period was much longer than in our study. The efficacy of this combined treatment in our study was similar to that reported by Oryan et al. (17). However, in contrast, we applied this combined treatment as a single injection.

Meyers et al.'s study (21) is the only study available in the medical literature on the effects of local administration of $\mathrm{HA}+\mathrm{CS}$ on the formation of adhesion after tendon repair in orthopedic practice. They reported that the mean adhesion strength and the tensile strength for the HA+CS-treated group was even lower compared with the control group; however, the difference was not statistically significant. In our study, local administration of the HA+CS solution following tendon repair prevented adhesion formation, inhibited inflammatory infiltration constituted by lymphocytes and macrophages, and facilitated regular arrangement of collagen fibrils. Although less adhesion and inflammation in macroscopic grading was observed in group 2 (high dose of $\mathrm{HA}+\mathrm{CS} ; 0.5 \mathrm{~mL}$ ) when compared to group 1 (low dose of $\mathrm{HA}+\mathrm{CS} ; 0.25 \mathrm{~mL}$ ), the grade of adhesion was not statistically significant difference between both treatment groups. Furthermore, the administration of the high dose $(0.5 \mathrm{~mL})$ of $\mathrm{HA}+\mathrm{CS}$ solution increased the ultimate stress endurance compared with the other groups in the biomechanical assessments. We hypothesized that the high dose of $\mathrm{HA}+\mathrm{CS}$ is suitable for tendon healing and prevention of peritendinous adhesion as well as the best stress endurance strength after extrasynovial tendon repair. Meyers et al. (21) thought that HA could cause tendon healing intrinsically rather than extrinsically and might block the extrinsic healing mechanism by inhibiting neutrophil migration and phagocytosis as well as fibroblast migration to the tendon, thus preventing adhesion. We think due to the positive results that $\mathrm{HA}+\mathrm{CS}$ contributed to intrinsic tendon healing.

Meyers et al.'s (21) results contradict our study results as well as those of previous studies $(6,11,14-17,31)$. In contrast to the study conducted by Meyers et al. (21), in our study; the grade, rigidity, density and severity of adhesion as well as inflammation were lower observed in both treatment groups when compared to the control group. However, the administration of the higher dose $(0.5 \mathrm{~mL})$ prevented the adhesion for- mation significantly and increased the ultimate stress endurance strength. In the present study, cartilaginous metaplasia, which was not mentioned in previous studies, was observed in groups 1 and 2. Increased tensile strength may be the result of the formation of cartilaginous metaplasia in the tendons of subjects treated with the higher dose of chondroitin sulfate. Kolodzinskyi et al. (32) reported that much higher friction was observed in the tendon treated with combining hylan G-F 20 with 1\% ethyl-3-(3-dimethylaminopropyl) carbodiimide hydrochloride, and $1 \% \mathrm{~N}$-hydroxysuccinimide bound the amine and carboxyl groups much more than the control group and the unmodified hylan G-F 20 group, which caused crystallization. They reported that these small, crystal-like particles might damage the tendon or pulley surface during repeated tendon motion against the pulley, leading to high gliding resistance owing to the rough surfaces.

Cartilaginous metaplasia might be due to the amount of highly concentrated CS in the HA solution. However, whether this condition leads to high gliding resistance owing to rough surfaces or particular damage in the tendon is not known. If $\mathrm{HA}+\mathrm{CS}$ causes only the tendon to heal intrinsically, it may not lead to high gliding resistance. Thus, this requires additional long-term studies.

This study is one of the few studies on the use of locally administrated $\mathrm{HA}+\mathrm{CS}$ in preventing tendon adhesion but has limitations such as the small sample size. Özer et al. (16) have evaluated the effects of glcN-CS on rat Achilles tendons. In this study, thirty rats were randomly grouped into two. Five rats in each group have sacrificed at 4,8 , and 12 weeks interval. Tensile strength of three tendon specimen from each group have tested biomechanically and two specimen were analysed histopathologically via immunohistochemical staining and hematoxylin and eosin staining. Ozboluk et al. (24) have compared the effects of periosteal autograft and human amniotic membrane on tendon healing. Forty-two rabbits have randomly divided into three groups with 14 rabbits in each. From each group seven rabbits for biomechanical and histopathological examinations have done 2 and 6 weeks postoperatively. We have identified the sample size, considering the studies. Despite this, we obtained encouraging results, which reinforce our belief that combined $\mathrm{HA}+\mathrm{CS}$ injection is a valid tool for preventing peritendinous adhesions after extrasynovial tendon repair such as the Achilles tendon, and is a treatment option. Further comprehensive studies are required to determine the long-term effects of cartilaginous metaplasia formation, an unexpected finding in this study, on surface friction. Moreover, further studies are required to determine whether cartilaginous metaplasia formation around tendons following local administration of HA+CS may be beneficial in treating cartilage-bone avulsion injuries and cartilage problems. 
Ethics Committee Approval: Ethics committee approval was received for this study from the institutional ethical board of animal Assays of Firat University (2012/2013, No: 118).

\section{Informed Consent: N/A.}

Peer-review: Externally peer-reviewed.

Author contributions: Concept - H.B.T., M.K., S.A.G.; Design - H.B.T., S.A.G., A.U., S.S.; Supervision - H.B.T., M.K., S.A.G.; Resource - H.B.T., A.U., M.K., Y.E.; Materials - H.B.T., M.K.,Y.E.; Data Collection and/or Processing - H.B.T., S.A.G., M.K., A.U.; Analysis and/or Interpretation - H.B.T., S.A.G., S.S.; Literature Search - H.B.T., S.A.G., A.U., S.S., Y.E.; Writing - H.B.T., S.A.G.; Critical Reviews - H.B.T., S.A.G., M.K., A.U., S.S., Y.E.

Conflict of Interest: No conflict of interest was declared by the authors.

Financial Disclosure: The authors declared that this study has received no financial support.

\section{REFERENCES}

1. Taras JS, Gray RM, Culp RW. Complications of flexor tendon injuries. Hand Clin 1994;10:93-109.

2. Ferguson RE, Rinker B. The Use of a hydrogel sealant on flexor tendon repairs to prevent adhesion formation. Ann Plast Surg 2006;56:54-8. [CrossRef]

3. Menderes A, Mola F, Tayfur V, Vayvada H, Barutcu A. Prevention of peritendinous adhesions following flexor tendon injury with seprafilm. Ann Plast Surg 2004;53:560-4. [CrossRef]

4. Kirker KR, Luo Y, Nielson JH, Shelby J, Prestwich GD. Glycosaminoglycan hydrogel films as bio-interactive dressings for wound healing. Biomaterials 2002;23:3661-71. [CrossRef]

5. Stark HH, Boyes JH, Johnson L, Ashworth CR. The use of paratenon, polyethylene film, or silastic sheeting to prevent restricting adhesions to tendons in the hand. J Bone Joint Surg Am 1977;59:908-13.

6. Zhao C, Sun YL, Amadio PC, Tanaka T, Ettema AM, An KN. Surface treatment of flexor tendon autografts with carbodiimidederivatized hyaluronic acid. An in vivo canine model. $J$ Bone Joint Surg Am 2006;88:2181-91. [CrossRef]

7. Komurcu M, Akkus O, Basbozkurt M, Gur E, Akkas N. Reduction of restrictive adhesions by local aprotinin application and primary sheath repair in surgically traumatized flexor tendons of the rabbit. J Hand Surg Am 1997;22:826-32. [CrossRef]

8. Akali A, Khan U, Khaw PT, McGrouther AD. Decrease in adhesion formation by a single application of 5-fluorouracil after flexor tendon injury. Plast Reconstr Surg 1999;103:151-8. [CrossRef]

9. Bates SJ, Morrow E, Zhang AY, Pham H, Longaker MT, Chang J. Mannose-6-phosphate, an inhibitor of transforming growth factor-beta, improves range of motion after flexor tendon repair. J Bone Joint Surg Am 2006;88:2465-72. [CrossRef]

10. Herzog M, Lindsay WK, McCain WG. Effect of beta-aminoproprionitrile on adhesions following digital flexor tendon repair in chickens. Surg Forum 1970;21:509-11.

11. Ozgenel GY. The effects of a combination of hyaluronic and amniotic membrane on the formation of peritendinous adhesions after flexor tendon surgery in chickens. J Bone Joint Surg Br 2004;86:301-7. [CrossRef]

12. Fraser JR, Laurent TC, Laurent UB. Hyaluronan: its nature, distribution, functions and turnover. J Intern Med 1997;242:27-33. [CrossRef]

13. Riley GP, Harrall RL, Constant CR, Chard MD, Cawston TE, Hazleman BL. Glycosaminoglycans of human rotator cuff tendons: changes with age and in chronic rotator cuff tendinitis. Ann Rheum Dis 1994;53:367-76. [CrossRef]

14. Hagberg L, Gerdin B. Sodium hyaluronate as an adjunct in adhesion prevention after flexor tendon surgery in rabbits. $J$ Hand Surg Am 1992; 17:935-41. [CrossRef]

15. Taguchi M, Zhao C, Sun YL, Jay GD, An KN, Amadio PC. The effect of surface treatment using hyaluronic acid and lubricin on the gliding resistance of human extrasynovial tendons in vitro. $J$ Hand Surg Am 2009;34:1276-81. [CrossRef]

16. Özer H, Taşkesen A, Kul O, Selek HY, Turanlı S, Köse K. Effect of glucosamine chondroitine sulphate on repaired tenotomized rat Achilles tendons. Eklem Hastalik Cerrahisi 2011;22:100-6.

17. Oryan A, Moshiri A, Meimandiparizi AH. Effects of sodiumhyaluronate and glucosamine-chondroitin sulfate on remodeling stage of tenotomized superficial digital flexor tendon in rabbits: a clinical, histopathological, ultrastructural, and biomechanical study. Connect Tissue Res 2011;52:329-39. [CrossRef]

18. Costantini E, Lazzeri M, Pistolesi D, Del Zingaro M, Frumenzi E, Boni A, et al. Morphological changes of bladder mucosa in patients who underwent instillation with combined sodium hyaluronic Acid-chondroitin sulphate (ialuril ${ }^{\circledR}$ ). Urol Int 2013;91:81-8. [CrossRef]

19. Frenkel S, DiCesare PE. Efficacy of chondroprotective agents. Curr Opin Orthop 2002;13:9-1. [CrossRef]

20. Chen L, Ling PX, Jin Y, Zhang TM. Hyaluronic acid in combination with chondroitin sulfate and hyaluronic acid improved the degeneration of synovium and cartilage equally in rabbits with osteoarthritis. Drug Discov Ther 2011;5:190-4. [CrossRef]

21. Meyers SA, Seaber AV, Glisson RR, Nunley JA. Effect of hyaluronic acid/chondroitin sulfate on healing of full-thickness tendon lacerations in rabbits. J Orthop Res 1989;7:683-9. [CrossRef]

22. Rydell N, Balazs EA. Effect of intra-articular injection of hyaluronic acid on the clinical symptoms of osteoarthritis and on granulation tissue formation. Clin Orthop Relat Res 1971;80:25-32. [CrossRef]

23. Tang JB, Shi D, Zhag QG. Biochemical and histologic evaluation of tendon sheath management. J Hand Surg Am 1996;21:900-8. [CrossRef]

24. Ozboluk S, Ozkan Y, Ozturk A, Ozdemir RM, Yanık K. The effects of human amniotic membrane and periosteal autograft on tendon healing: experimental study in rabbits. J Hand Surg Eur Vol 2010;35:262-8. [CrossRef] 
25. Kuzma JW, Bohnenblust SE. Basic statistics for the health sciences. ( $5^{\text {th }}$ ed.).New York, McGraw-Hill: Humanities/Social Sciences/Languages; 2005:180.

26. Sharma P, Maffulli, N. Tendon injury and tendinopathy: healing and repair. J Bone Joint Surg Am 2005;87:187-202. [CrossRef]

27. Peterson WW, Manske PR, Dunlap J, Horwitz DS, Kahn B. Effect of various methods of restoring flexor sheath integrity on the formation of adhesions after tendon injury. J Hand Surg Am 1990;15:48-56. [CrossRef]

28. Khanna A, Friel M, Gougoulias N, Longo UG, Maffulli N. Prevention of adhesions in surgery of the flexor tendons of the hand: what is the evidence? Br Med Bull 2009;90:85-109. [CrossRef]
29. Weiss C, Suros JM, Michalow A, Denlinger J, Moore M, Tejeiro W. The role of Na-hylan in reducing postsurgical tendon adhesions: Part 2. Bull Hosp Jt Dis Orthop Inst 1987;47:31-9.

30. McCarty MF. Glucosamine for wound healing. Med Hypotheses 1996;47:273-5. [CrossRef]

31. Tatari H, Özkal S, Skiak E, Skiak E, Destan H, Ulukus C, et al. Comparison of early and late term effects of hylan G-F 20 in Achilles tendonitis: an experimental study. Joint Dis Rel Surg 2005; 16:215-23.

32. Kolodzinskyi MN, Zhao C, Sun YL, An KN, Thoreson AR, Amadio PC, et al. The effects of hylan g-f 20 surface modification on gliding of extrasynovial canine tendon grafts in vitro. $J$ Hand Surg Am 2013;38:231-6. [CrossRef] 